\title{
1 Competence-associated peptide BriC alters fatty acid biosynthesis in
} 2 Streptococcus pneumoniae

4 Running Title: Secreted peptide alters fatty acid biosynthesis

Authors: Surya D. Aggarwal ${ }^{1}$, Jessica M. Gullett ${ }^{2}$, Tara Fedder ${ }^{1}$, J. Pedro F. Safi ${ }^{1}$, Charles O.

7 Rock ${ }^{2}$, N. Luisa Hiller ${ }^{1^{*}}$

$9{ }^{1}$ Department of Biological Sciences, Carnegie Mellon University, Pittsburgh, PA

10 'Department of Infectious Diseases, St. Jude Children's Research Hospital, Memphis, TN

*corresponding author: Ihiller@andrew.cmu.edu

15 Keywords: Streptococcus pneumoniae, fatty acid biosynthesis, membrane

16 phospholipid composition, biofilms, cell-cell communication, competence 


\section{ABSTRACT} peptide.

Membrane lipid homeostasis is required for bacteria to survive in a spectrum of host environments. This homeostasis is achieved by regulation of fatty acid chain length and of the ratio of saturated to unsaturated fatty acids. In the pathogen Streptococcus pneumoniae, fatty acid biosynthesis is encoded by a cluster of fatty acid biosynthesis (fab) genes (FASIl locus) whose expression is controlled by the FabT repressor. Encoded immediately downstream of the FASIl locus is BriC, a competence-induced, cell-cell communication peptide that promotes biofilm development as well as nasopharyngeal colonization in a murine model of pneumococcal carriage. Here, we demonstrate that briC is co-transcribed with genes of the fab gene cluster and that a reduction of briC levels, caused by decoupling its transcription from fab gene cluster, negatively impacts biofilm development. BriC elevates fabT transcription, which is predicted to alter the balance of saturated and unsaturated fatty acids produced by the pathway. We find that briC inactivation results in a decreased production of unsaturated fatty acids that impact the membrane properties by decreasing the abundance of diunsaturated phosphatidylglycerol molecular species. We propose that the link between BriC, FabT and phospholipid composition contributes to the ability of S. pneumoniae to alter membrane homeostasis in response to the production of a quorum-sensing 


\section{IMPORTANCE}

39 Adaptation of bacteria to their host environment is a key component of colonization and

40 pathogenesis. As an essential component of bacterial membranes, fatty acid

41 composition contributes to host adaptation. Similarly, so does cell-cell communication,

42 which serves as a mechanism for population levels responses. While much is known

43 about the pathways that control the biosynthesis of fatty acids, many questions remain

44 regarding regulation of these pathways and consequently the factors that impacts the

45 balance between saturated and unsaturated fatty acids. We find that BriC, a cell-cell

46 communication peptide implicated in biofilm regulation and colonization, is both

47 influenced by a fatty acid biosynthesis pathway and impacts this same pathway. This

48 study identified a link between cell-cell communication, fatty acid composition, and

49 biofilms and, in doing so, suggests that these pathways are integrated into the networks

50 that control pneumococcal colonization and host adaptation. 


\section{INTRODUCTION}

54 Streptococcus pneumoniae (pneumococcus) is a major human pathogen. Worldwide, it

55 is responsible for over one million annual deaths in children and the elderly (1). Drug

56 resistant pneumococcus is classified as a serious threat by the CDC, such that there is

57 a need for new therapies. Fatty acid synthesis is a core function of the cell, and as such

58 a potential drug target.

60 In bacteria, fatty acids can be acquired by two independent pathways: de novo

61 production or uptake from host cells. De novo phospholipid synthesis in pneumococcus

62 is carried out by thirteen dissociated fatty acid synthesis genes that are a part of the

63 FASIl system. These genes are encoded in a single cluster on the genome and act to

64 elongate and modify acetyl-CoA primers to produce saturated and unsaturated acyl

65 chains attached to an acyl carrier protein (ACP). Attachment to ACP allows binding of

66 any acyl chain to FASII enzymes. Uptake from the host is mediated by the fatty acid

67 kinase (Fak) system that incorporates exogenous fatty acids into the phospholipid

68 membrane $(2,3)$.

70 In pneumococcus, the regulation of the FASIl locus is under control of FabT, which

71 autoregulates itself and represses most FASII genes except for FabM $(4,5)$. FabT is

72 constitutively expressed and binds with low affinity to the promoter regions of fabT and

73 fabK, thereby permitting some transcription of genes in the FASIl locus. Long chained

74 acyl-ACPs, from FASII or exogenous sources, regulate FASII through FabT. 
75 Specifically, the FabT-acyl-ACP complex which strengthens FabT's affinity for DNA and

76 blocks FASII gene transcription $(2,3,6)$.

78 In the current model, the balance between saturated (SFA) and unsaturated (UFA) fatty

79 acids requires an isomerase, FabM. FabM catalyzes the conversion of trans-2- to cis-3-

80 enoyl-ACP $(4,5,7)$. The SFA:UFA ratio is determined by the competition of FabM and

81 FabK for the available enoyl-ACP. If FabK utilizes the enoyl-ACP, SFA are produced,

82 and if FabM utilizes the intermediate, UFA are produced. Because FabM catalyzes an

83 equilibrium reaction, its overexpression has little impact on UFA levels compared to the

84 larger effects of independently manipulating either the FabK or FabF levels (Lu and

85 Rock, 2006). Because FabT regulates FabK and FabF, but not FabM, modulation of

86 FabT repression levels by the combination of fabT expression and/or acyl-ACP levels

87 impacts the balance between SFA and UFA synthesis.

89 In many Gram-positive bacteria, including pneumococcus, uptake of fatty acids blocks

90 de novo synthesis by triggering an inhibition of endogenous fatty acid synthesis (via

91 FabT in the pneumococcus). For example, like S. pneumoniae, Enterococcus faecalis

92 encodes two acp genes: acpA encoded within the fatty acid synthesis ( fab) operon and

$93 a c p B$ encoded in an operon with the acyl-ACP:phosphate transacylase pls $X$. Long chain

94 acyl-ACP-dependent repression via exogenous fatty acids is selective for AcpB in $E$.

95 faecalis. The transcription of two ACPs, present in different neighborhoods, ensures that

96 acyl-ACPs originating from a host will regulate FASIl synthesis; incoming acyl chains

97 are paired with $A c p B$ while $a c p A$ and fabT are repressed (8). In this manner many 
98 bacteria, via their ability to synthesize membrane from fatty acids acquired from the

99 host, can survive without de novo synthesis as long as external sources are available.

100 Another factor that regulates FASII is the WalRK histidine kinase signal transduction

101 system (also known as YycFG and VicRK). Overexpression of the response regulator,

102 WalR, modifies the expression of twelve FAS genes and results in cells phenotypically

103 similar to fabT mutants that have longer-chained fatty acids (9).

104

105 Immediately downstream of the pneumococcal FASII locus is the small peptide, BriC

106 (biofilm regulator induced by competence). BriC is a ribosomally-synthesized peptide

107 that belongs to the class of double-glycine secreted peptides in pneumococcus (10).

108 The expression of briC is induced directly by ComE, the master regulator of

109 competence, and BriC is secreted via the competence-associated ABC transporter,

110 ComAB (11). Some pneumococcal isolates, including those from the clinically important

111 PMEN1 and PMEN14 lineages, encode a RUPB1-containing briC promoter which

112 provides a competence-independent induction of briC in an otherwise competence-

113 dependent pathway. The production and secretion of BriC promote late stage biofilm

114 development in vitro, and nasopharyngeal colonization in a murine model of

115 pneumococcal carriage (11).

116

117 Here, we show that briC is co-transcribed with genes of the fab gene cluster, and that its

118 expression modulates the membrane fatty acid composition of S. pneumoniae. In

119 accordance with the role of BriC in promoting biofilm development, decreasing levels of

120 bric by decoupling its transcription from the fab gene cluster negatively influences 
121 biofilm development. The briC knockout strains have altered levels of fabT expression

122 coupled with a distinct shift in membrane phospholipid molecular species composition.

123 Thus, BriC contributes to the regulation of $S$. pneumoniae FASIl either directly or

124 indirectly by altering the transcription of the FabT regulon.

125

126

127

\section{RESULTS}

\section{briC is co-transcribed with genes of the fab gene cluster}

BriC is a competence-induced gene product, yet a basal level of transcription is observed even in the absence of competence (11). The coding region for briC is immediately downstream of the fab gene cluster (159 base pairs downstream of acc $A$ (spd_0390) in strain R6D) (Fig. 1A). Thus, we hypothesized that the basal levels of briC may be attributed to its co-transcription with genes of the fab gene cluster. Since the genes spanning from fabK through accA are transcribed as a polycistronic unit (4), we tested whether briC is transcribed with the last two genes of this operon: $a c c D$ and accA. We performed PCR on cDNA synthesized using RNA from planktonic pneumococcal cultures as a template and used it to determine whether transcripts extend from $a c c D$ or accA to briC (Fig. 1B.i). The results indicated that briC is cotranscribed with genes of the fab gene cluster. An in silico search reveals two putative promoter sequences, which may drive the co-transcription of briC and genes of the fab gene cluster (Fig. 1A). The first is upstream of fabK, and the second is within the coding sequence of $f a b G$. These promoters contain putative -35 and -10 regions, and are in agreement with promoters previously identified by Cappable-seq (12). 
145 To study the importance of co-regulation of briC with genes of the fab gene cluster, we

146 opted to decouple the transcription of briC from that of the fab gene cluster. We

147 generated a strain with a transcriptional terminator immediately downstream of accA

148 (term ${ }^{+}$strain). As expected, while a transcript with briC alone is present in the term ${ }^{+}$

149 strain, the accA-briC transcript is no longer detected (Fig. 1B.ii). Thus, introduction of

150 the terminator relieved briC of its co-transcription with genes of the fab gene cluster.

151 Further, the competence-dependent induction of briC was preserved in the term ${ }^{+}$strain

152 (briC was induced 3.26-fold following CSP treatment). We conclude that briC

153 expression can be regulated in concurrence with the fab gene cluster, as well as

154 independently via CSP.

Co-expression of briC with genes from the fab gene cluster contributes to biofilm

\section{7 development}

158 We have previously demonstrated that BriC promotes biofilm development (11). Since

159 briC can be co-transcribed with the upstream fatty acid genes, we hypothesized that

160 decoupling briC from fatty acid synthesis would negatively impact biofilm development.

161 In support, we observe an approximately 15\% reduction in biofilm biomass and

162 thickness in the term+ cells relative to WT cells, when testing biofilms at $72 \mathrm{~h}$ post-

163 seeding on abiotic surfaces (Fig. 2A, B). While maximum thickness is a measure of the

164 distance of highest point or the peak from the bottom layer containing biomass, the

165 average thickness over biomass is an indicator of the general shape and spatial size of

166 the biofilm. 
168 To establish whether the biofilm defect was associated with an alteration in the

169 competence-dependent induction of briC, we tested biofilm development in cells where

170 briC was regulated in a competence-independent fashion. We made use of a strain

171 where briC is overexpressed due to a promoter that encodes a RUP sequence

172 (PbriClong-briC), and where comE is deleted (henceforth, referred to as $\Delta$ comE//briC-

$173 \mathrm{OE})$. We have previously shown that expression of briC from PbriClong

174 bypasses the impact of comE deletion on biofilm development (11). Thus, we tested

175 whether decoupling transcription of briC from the fab gene cluster by the introduction of

176 terminator $\left(\right.$ term $\left.^{+}\right)$influences biofilms in the $\Delta$ comE//briC-OE background. Akin to the

177 WT background, presence of the terminator $\left(\right.$ term $\left.^{+}\right)$leads to a significant reduction in

178 biomass and thickness of biofilms in the $\Delta$ comE//briC-OE strain compared to the term

179 strain in the same background (Fig. 2C, D). These results strongly suggest that

180 induction of briC via control of the fab gene cluster contributes to the role of $\mathrm{BriC}$ in

181 promoting biofilm development. Thus, regardless of the mechanism of induction,

182 increased expression of briC positively contributes to biofilm development.

184 BriC contributes to membrane compositional homeostasis

$185 \mathrm{BriC}$ is a secreted peptide that is co-transcribed with genes of the fab gene cluster.

186 Owing to this genomic organization, we investigated whether BriC played any functional

187 role in altering fatty acid synthesis in pneumococcal cells. FabT regulates genes of the

188 fab gene cluster, including itself (4). To test the impact of BriC on expression of fabT,

189 we generated a fusion of the fabT promoter with lac $Z$ and measured the $\beta$ -

190 galactosidase activity in WT and $\triangle$ briC strains. We observed approximately a $35 \%$ 
191 decrease in $\beta$-galactosidase activity in $\Delta b r i C$ relative to WT cells (Fig. 3). We conclude

192 that BriC enhances fabT transcription from its autoregulated promoter. The reduced

193 expression of fabT signals repression of the entire regulon suggesting that the absence

194 of briC expression would alter the membrane phospholipid composition. Specifically, the

195 repression of the FabT regulon would increase UFA biosynthesis at the expense of SFA

196 (4).

198 This prediction was tested by determining the composition of the membrane 199 phospholipids in wild-type and $\triangle$ briC strains. Pneumococcus uses the FASIl system to 200 produce acyl chains which are transferred, via positionally-specific acyltransferases, to 201 the 1- and 2-positions of glycerol-3-phosphate (G3P) that determine the composition of 202 phosphatidic acid, the precursor to all membrane glycerolipids. We employed liquid 203 chromatography-mass spectrometry (LC-MS) to determine the phosphatidylglycerol (PG) 204 membrane molecular species composition in wild-type, $\Delta b r i C$, and briC-overexpressing 205 cells (briC-OE) cells. LC-MS analysis determines the total carbon number of acyl chains 206 in the 1- and 2- position of the G3P backbone, as well as the number of double bonds, 207 and is an accurate representation of the acyl chain production of pneumococcal strains.

209 The wild-type strain made primarily mono- and di-unsaturated PG molecular species with 210 the predominant peaks containing 32, 34, or 36 carbons (Fig. 4A). The molecular species 211 distribution in these samples consisted of 16:0,16:1, 18:0, and 18:1 acyl chains and is 212 typical of other pneumococcal strains $(2,13)$. The acyl chains comprising the predominant

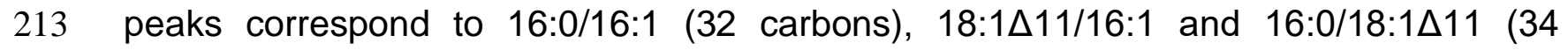


214 carbons), and 18:1 $\Delta 11 / 18: 1 \Delta 11$ (36 carbons) (2). In the $\Delta$ briC strain, we observed a

215 reduction in the unsaturated molecular species at each carbon number in comparison to

216 the wild-type strain (Fig. 4B). None of these changes were observed in the briC-OE cells

217 relative to the WT strain (Fig. $\mathbf{4 C}$ ). The quantification of three replicates shows a

218 consistent decrease in the unsaturated PG molecular species at each carbon number

219 (Fig. 4D). We conclude that FASIl of the $\triangle b r i C$ strain produces a lower amount of 220 unsaturated fatty acids that, in turn, alters the membrane phospholipid molecular species

221 composition. Together, these results suggest that BriC, via fabT, alters the lipid 222 composition of pneumococcal cell membranes, tilting the balance toward unsaturated 223 fatty acids.

\section{DISCUSSION}

226 Long chain fatty acids serve as essential components of bacterial membranes and 227 compositional changes therein are essential for cellular survival and environmental 228 adaptation. The biosynthesis of fatty acids is tightly regulated. While much is known 229 about the regulation and synthesis of the cell membrane, gaps remain regarding the 230 nature of the molecular signals that activate this pathway. Here we present evidence

231 that BriC, a small, secreted peptide implicated in cell-cell communication, is co-

232 transcribed with genes of the fab gene cluster and participates in regulation of

233 phospholipid membrane composition via a role in fabT induction. Moreover, as we have

234 previously shown that BriC promotes biofilms, we demonstrate that this phenotype is

235 linked to co-regulation between FASIl genes and briC. 
237 The demonstration that briC is co-transcribed with the fab gene cluster, reveals the third

238 regulatory pathway for briC regulation. The regulation of briC by ComE, via the ComE-

239 binding box, is conserved across strains in the species and demonstrates a tight link

240 between competence induction and briC expression (11). In a subset of strains, the

241 transcription of briC is also influenced by the presence of transposable RUP (repeat unit

242 of pneumococcus) sequence in its promoter (11). RUP allows for a CSP-independent

243 pathway for the expression of briC. The discovery that briC can be co-transcribed with

244 the fab gene cluster, reveals a third pathway for regulation. Further, it suggests that

245 BriC may be regulated by multiple two component systems, ComE and WalRK. WalRK

246 triggers the activation of the fab gene cluster and briC is co-transcribed with genes of

247 this locus, thus it is likely that WalRK promotes briC expression. The activation of briC

248 by multiple pathways is consistent with a gene network where BriC is positioned to

249 respond to diverse regulatory inputs. Signaling through WalRK is important in

250 maintenance of cell shape, division, pathogenesis and in the response to stresses such

251 as oxidative stress (14-16). Competence activation has also been described of as a

252 general SOS response pathway, as well as a sensor of cell density. Thus, the

253 colonization factor BriC may respond to cell density and stress conditions and induce

254 changes in membrane composition and biofilm growth.

256 We have previously demonstrated that BriC promotes biofilm development and

257 nasopharyngeal colonization (11). In this study, we show that BriC influences

258 membrane lipid composition. Are these phenotypes connected? A study comparing

259 transcriptional profiles of pneumococcal cells growing in biofilm versus planktonic mode 
260 of growth found an upregulation of fatty acid biosynthesis genes during biofilm

261 development (17). A role for fatty acid biosynthesis and metabolism in biofilm formation

262 has also been reported in other bacteria including Bacillus subtilis, Staphylococcus

263 aureus and Pseudomonas aeruginosa (18-21). It seems plausible that BriC-dependent

264 changes in membrane properties contribute to biofilm development. Alternatively,

265 enhanced cell-cell signaling associated with a biofilm-mode of growth, may enhance

266 BriC-mediated effects on lipid composition, and serve as a link between biofilms and

267 lipid composition.

269 In this work, we have revealed a link between a cell-cell communication peptide and the

270 regulation of fatty acid composition. Our findings reveal that briC is co-regulated with the

271 fab gene cluster, and, reciprocally, that it impacts membrane homeostasis by

272 influencing transcription of the FabT regulon.

273

\section{MATERIALS \& METHODS}

\section{Bacterial strains \& growth conditions}

276 The experimental work was performed with the R6D wild-type strain of Streptococcus

277 pneumoniae (Hun663.tr4) as this was used in our previous studies of BriC (11).

278 Colonies were grown from frozen stocks by streaking on TSA-II agar plates

279 supplemented with 5\% sheep blood (BD BBL, New Jersey, USA). Unless otherwise

280 stated, streaked colonies were picked and inoculated in fresh Columbia broth (Remel

281 Microbiology Products, Thermo Fisher Scientific, USA) whose pH was adjusted to 6.6 
282 by the addition of $1 \mathrm{M} \mathrm{HCl}$ and thereafter, incubated at $37^{\circ} \mathrm{C}$ and $5 \% \mathrm{CO} 2$ without

283 shaking.

\section{Construction of mutants}

286 Mutant strains were constructed by using site-directed homologous recombination and

287 selected by the addition of an antibiotic resistance marker. The term ${ }^{+}$transformation

288 construct was generated by ligating the amplified flanking regions with antibiotic

289 resistance cassette followed by transcriptional terminator B1002. Between 1-2kb of

290 flanking regions upstream and downstream of the region of interest were amplified from

291 parental strain using Q5 2x Master Mix (New England Biolabs, USA). The antibiotic

292 resistance gene ermB was amplified from S. pneumoniae SV35-T23. The sequence of

293 the terminator was added to the primers. The PCR products were assembled by Gibson

294 assembly using NEBuilder HiFi DNA Assembly Cloning Kit (New England Biolabs,

295 USA).

297 Bacterial transformations

298 Bacterial target strains were grown in acidic Columbia broth until an $\mathrm{OD}_{600}$ of 0.05 and

299 followed by addition of $125 \mu \mathrm{g} / \mathrm{mL}$ of CSP1 (sequence: EMRLSKFFRDFILQRKK;

300 purchased from GenScript, NJ, USA) and $1 \mu \mathrm{g}$ of transforming DNA. The cultures were

301 incubated at $37^{\circ} \mathrm{C}$ and $5 \% \mathrm{CO} 2$ without shaking for 2 hours followed by plating on

302 Columbia agar plates containing the appropriate antibiotic: kanamycin $(150 \mu \mathrm{g} / \mathrm{ml})$, 303 erythromycin $(2 \mu \mathrm{g} / \mathrm{ml})$ and incubating overnight. Resistant colonies were cultured in 
304 selective media, and the colonies confirmed using PCR. Bacterial strains generated in

305 this study are listed in Supplementary Table S1.

306

\section{RNA extractions}

308 For qRT-PCR, samples were grown until an $\mathrm{OD}_{600}$ of 0.1 , followed by CSP1 treatment

309 for 0 and 10 minutes. This was followed by addition of RNALater to preserve RNA

310 quality and pelleting of cells. The cells were lysed by resuspending the pellet in an

311 enzyme cocktail ( $2 \mathrm{mg} / \mathrm{ml}$ proteinase $\mathrm{K}, 10 \mathrm{mg} / \mathrm{ml}$ lysozyme, and $20 \mu \mathrm{g} / \mathrm{ml}$ mutanolysin).

312 Then, RNA was isolated using the RNeasy kit (Genesee Scientific, USA) following

313 manufacturer's instructions. Contaminant DNA was removed by treating with DNase

$314(2 \mathrm{U} / \mu \mathrm{L})$ at $37^{\circ} \mathrm{C}$ for at least 45 mins followed by RNA purification using the RNeasy kit.

315 The RNA concentration was measured by NanoDrop 2000c spectrophotometer

316 (Thermo Fisher Scientific, USA). The purity of the RNA samples was confirmed by the

317 absence of a DNA band on an agarose gel obtained upon running PCR products for the

318 samples amplified for gapdh.

\section{0 qRT-PCR}

321 Purified RNA was used as a template for first-strand cDNA synthesis by using qScript

322 cDNA Synthesis Kit (Quantabio, USA) followed by qRT-PCR using PerfeCTa SYBR

323 Green SuperMix (Quantabio, USA) in an Applied Biosystems 7300 Instrument (Applied

324 Biosystems, USA).16S rRNA counts were used for normalization. 


\section{Biofilm development assay}

328 For biofilm development assays, pneumococcal cells were grown in acidic Columbia

329 broth until the cultures reached an $\mathrm{OD}_{600}$ of 0.05 . Then, $3 \mathrm{mls}$ of culture was seeded on

$33035 \mathrm{MM}$ glass bottom culture dishes (MatTek Corporation, USA) and incubated at $37^{\circ} \mathrm{C}$

331 and $5 \% \mathrm{CO} 2$ without shaking. At $24 \mathrm{~h}$ and $48 \mathrm{~h}$ post-seeding, the supernatant from the

332 dishes was carefully aspirated with a pipette, followed by the addition of the same

333 volume of pre-warmed media made at one-fifth of the original concentration. The

334 biofilms were fixed for analysis at $72 \mathrm{~h}$ post-seeding. For fixation, supernatants were

335 aspirated, and the biofilms were washed thrice with PBS to remove non-adherent and

336 weakly adherent cells. Thereafter, biofilms were fixed with $4 \%$ paraformaldehyde

337 (Electron Microscopy Sciences, USA) for 20 minutes. The biofilms were then washed

338 with PBS three times and stained for confocal microscopy.

\section{Confocal microscopy \& quantification of biofilms}

341 SYTO59 Nucleic Acid Stain (Life Technologies, USA) was used to stain biofilms as per

342 manufacturer's instructions for 30 minutes. The stained biofilms were then washed three

343 times and preserved in PBS for imaging. Imaging was performed on the stage of Carl

344 Zeiss LSM-880 META FCS confocal microscope, using 561nm laser for SYTO dye. Z-

345 Stacks were captures at every $0.46 \mu \mathrm{m}$, imaged from the bottom to the top of the stack

346 until cells were visible, and reconstructed in Carl Zeiss black edition and ImageJ. The

347 biofilm stacks were analyzed using COMSTAT2 plug-in for ImageJ (22) and the different

348 biofilm parameters (biomass, maximum thickness, and average thickness over

349 biomass) were quantified. For depiction of representative reconstructed Z-stacks, empty 
350 slices were added to the images so the total number of slices across all the samples

351 were the same. The reconstructed stacks were pseudo-colored according to depth

352 using Carl Zeiss black edition.

\section{Construction of lacZ fusions}

355 Chromosomal transcriptional lacZ-fusions to the target promoters were constructed as 356 previously described (11). Briefly, lacZ-fusions were generated in the $b g a A$ gene using

357 modified integration plasmid pPP2. The fabT and fabK promoter regions were amplified 358 from R6D strains and modified to contain Kpnl and Xbal restriction sites. The products

359 were then digested with restriction enzymes followed by sticky-end ligation of the 360 products. These plasmids were transformed into E. coli TOP10 strain, and selected on

361 LB (Miller's modification, Alfa Aesar, USA) plates, supplemented with ampicillin

$362(100 \mu \mathrm{g} / \mathrm{ml})$. The plasmids were then purified by using E.Z.N.A. Plasmid DNA Mini Kit II

363 (OMEGA bio-tek, USA), and transformed into pneumococcal strains and selected on

364 Columbia agar plates supplemented with kanamycin $(150 \mu \mathrm{g} / \mathrm{ml})$.

$\beta$-galactosidase assay

$367 \beta$-galactosidase assay was performed as previously described (23). For assaying the $\beta$ -

368 galactosidase activity, cells were grown in TY media (TH medium supplemented with

$3690.5 \%$ yeast extract) until exponential phase and frozen. The frozen cells were thawed

370 and re-inoculated in TY media and grown until mid-exponential phase for analysis. 


\section{Membrane Lipid Composition Analysis}

374 Bacterial cells were inoculated in CDM-Glucose and incubated at $37^{\circ} \mathrm{C}$ and $5 \% \mathrm{CO} 2$

375 without shaking until they reached an $\mathrm{OD}_{600}$ of 0.5 . CDM-Glucose was prepared as 376 previously described (PMID: 23505518). The cells were then pelleted by centrifuging at

377 4000rpm for 15 minutes followed by washing with PBS three times. The PBS was 378 decanted and the washed cells were frozen at $-20^{\circ} \mathrm{C}$ before being resuspended in $1 \mathrm{ml}$ 379 deionized water and vortexed. Lipids were resuspended in chloroform:methanol (2:1) and 380 extracted using the Bligh and Dyer method (24). PG was analyzed using a Shimadzu 381 Prominence UFLC attached to a QTrap 4500 equipped with a Turbo V ion source (Sciex). 382 Samples were injected onto an Acquity UPLC BEH HILIC, $1.7 \mu \mathrm{m}, 2.1$ x $150 \mathrm{~mm}$ column 383 (Waters) at $45^{\circ} \mathrm{C}$ with a flow rate of $0.2 \mathrm{ml} / \mathrm{min}$. Solvent $\mathrm{A}$ was acetonitrile, and solvent $\mathrm{B}$ 384 was $15 \mathrm{mM}$ ammonium formate, $\mathrm{pH}$ 3. The HPLC program was the following: starting 385 solvent mixture of $96 \%$ A / 4\% B, 0 to 2 min isocratic with 4\% B; 2 to 20 min linear gradient 386 to $80 \%$ B; 20 to 23 min isocratic with $80 \%$ B; 23 to 25 min linear gradient to $4 \%$ B; 25 to 38730 min isocratic with 4\% B. The QTrap 4500 was operated in the Q1 negative mode. The 388 ion source parameters for Q1 were: ion spray voltage, -4500 V; curtain gas, 25 psi; 389 temperature, $350^{\circ} \mathrm{C}$; ion source gas $1,40 \mathrm{psi}$; ion source gas 2, 60 psi; and declustering 390 potential, $-40 \mathrm{~V}$. The system was controlled by the Analyst ${ }^{\circledR}$ software (Sciex). The sum 391 of the areas under each peak in the mass spectra was calculated, and the percent of 392 each molecular species present was calculated with LipidView software (Sciex). 


\section{Statistical tests}

397 For comparisons between only two groups, student's $t$-test was performed. $p$-values of

398 less than 0.05 were considered to be statistically significant. Statistical analyses of the

399 ratios of PG molecular species were determined using an ANOVA and Tukey's Test.

400

401

402

403

Acknowledgements. We thank Matthew Frank for mass spectrometry and Jason

404 Rosch for thoughtful suggestions. This research was supported by NIGMS (GM034496 to CR), the American Lebanese Associated Charities (CR), NIAID (R01 Al139077-01A1 to NLH), the Eberly Family Trust (NLH) and Glen de Vries Fellowship (SDA). The content is solely the responsibility of the authors and does not necessarily represent the official views of the National Institutes of Health. 
409 Fig. 1. briC is co-transcribed with genes of the fab gene cluster. (A) Genomic

410 organization of the fab gene cluster and bric. The fab gene cluster consists of thirteen

411 genes ranging from fabM to accA. FabT regulates the expression of two operons: fabT-

$412 a c p P$ and fabK-accA. briC is situated downstream of accA. Small dark green boxes

413 indicate promoters with a FabT-binding site, while light green box indicates an additional

414 putative promoter. Inset: term ${ }^{+}$strain contains ermB cassette followed by the terminator

415 B1002 immediately downstream of accA. Transcripts fabT-acpP and fabK-accA are

416 labelled. Labels $A, B$ and $C$ refer to the different transcripts tested below. (B.i) briC is

417 transcriptionally linked to genes of the fab gene cluster. gDNA and cDNA from WT

418 strain were amplified using primers expected to produce three different amplicons: $A$ :

419 briC only (177bp), B: accA-briC (1088bp), C: accD-briC (1912bp), visualized on agarose

420 gel. (B.ii) Insertion of the terminator relieves co-transcription of briC with accA. gDNA

421 and cDNA from term ${ }^{+}$strain was amplified using primers expected to produce amplicons

422 A, B and C (as above), visualized on agarose gel. cDNA for term+ shows a positive

423 band only for briC alone. Amplicons B \& $C$ from gDNA have a higher molecular size in

$424 t^{+}{ }^{+}$relative to WT because of the presence of ermB and terminator (additional

425 1051bp).

\section{Fig. 2. Co-expression of briC with the fab gene cluster promotes biofilm} development. (A, C) Representative confocal microscopy images showing top view of the reconstructed biofilm stacks of term and term ${ }^{+}$cells in (A) WT and (C) $\triangle$ comE//briCOE genomic background of strain R6D stained with SYTO59 dye at 72h. Images are pseudo-colored according to depth (scales shown). (B, D) COMSTAT2 quantification of $72 \mathrm{~h}$ biofilm images. Y-axis denotes units of measurement: $\mu \mathrm{m}^{3} / \mu \mathrm{m}^{2}$ for biomass, and $\mu \mathrm{m}$ for maximum thickness and average thickness over biomass. Error bars represent standard error of the mean calculated for biological replicates $(n=3) ;{ }^{* *} p<0.01,{ }^{* * *}$ $p<0.001$ and $^{* * * *} p<0.0001$ using Student's $t$-test.

Fig. 3. BriC induces the levels of fabT. $\beta$-galactosidase assay comparing the LacZ activity of fabT promoter in WT and $\Delta$ briC cells. Cells were grown in TY medium until mid-log phase. Y-axis denotes promoter activity in Miller Units expressed in nmol $\mathrm{p}$-nitrophenol $/ \mathrm{min} / \mathrm{ml}$. Error bars represent standard error of the mean for biological replicates $(n=3)$; "ns" denotes statistically non-significant comparison, ${ }^{* *} p<0.01$ using Student's $t$-test. acids. Mass spectrometry analysis of the PG molecular species of R6D pneumococcal strain and its isogenic mutants. Representative spectrum of PG molecular species of (A) WT, (B) $\triangle$ briC, and (C) briC-OE strains. The most unsaturated molecular species for 
448 each carbon number are highlighted in red. (D) The PG species from three biological 449 replicates were quantified and the ratios for each carbon number were calculated. $p$ 450 values were calculated in Prism software using ANOVA followed by Tukey's test for 451 multiple comparisons. 


\section{BIBLIOGRAPHY}

455 1. GBD 2016 Lower Respiratory Infections Collaborators. 2018. Estimates of the global, regional, and national morbidity, mortality, and aetiologies of lower respiratory infections in 195 countries, 1990-2016: a systematic analysis for the Global Burden of Disease Study 2016. Lancet Infect Dis 18:1191-1210.

2. Gullett JM, Cuypers MG, Frank MW, White SW, Rock CO. 2019. A fatty acidbinding protein of Streptococcus pneumoniae facilitates the acquisition of host polyunsaturated fatty acids. J Biol Chem 294:16416-16428.

3. Parsons JB, Broussard TC, Bose JL, Rosch JW, Jackson P, Subramanian C, Rock CO. 2014. Identification of a two-component fatty acid kinase responsible for host fatty acid incorporation by Staphylococcus aureus. Proc Natl Acad Sci U S A 111:10532-10537.

4. Lu Y-J, Rock CO. 2006. Transcriptional regulation of fatty acid biosynthesis in Streptococcus pneumoniae. Mol Microbiol 59:551-566.

5. Marrakchi H, Choi K-H, Rock CO. 2002. A new mechanism for anaerobic unsaturated fatty acid formation in Streptococcus pneumoniae. J Biol Chem 277:44809-44816.

6. Zuo G, Chen ZP, Jiang YL, Zhu Z, Ding C, Zhang Z, Chen Y, Zhou CZ, Li Q. 2019. Structural insights into repression of the Pneumococcal fatty acid synthesis pathway by repressor FabT and co-repressor acyl-ACP. FEBS Lett 593:27302741.

7. Fozo EM, Quivey Jr. RG. 2004. The fabM gene product of Streptococcus mutans is responsible for the synthesis of monounsaturated fatty acids and is necessary for survival at low pH. J Bacteriol 186:4152-4158.

8. Zhu L, Zou Q, Cao X, Cronan JE. 2019. Enterococcus faecalis encodes an atypical auxiliary acyl carrier protein required for efficient regulation of fatty acid synthesis by exogenous fatty acids. MBio 10:e00577-19.

9. Mohedano ML, Overweg K, de la Fuente A, Reuter M, Altabe S, Mulholland F, de Mendoza D, López P, Wells JM. 2005. Evidence that the essential response regulator YycF in Streptococcus pneumoniae modulates expression of fatty acid biosynthesis genes and alters membrane composition. J Bacteriol 187:23572367.

10. Aggarwal SD, Yesilkaya H, Dawid S, Hiller NL. 2020. The pneumococcal social network. PLoS Pathog 16:e1008931.

11. Aggarwal SD, Eutsey R, West-Roberts J, Domenech A, Xu W, Abdullah IT, Mitchell AP, Veening J-WW, Yesilkaya H, Hiller NL. 2018. Function of BriC peptide in the pneumococcal competence and virulence portfolio. PLoS Pathog 14:e1007328.

12. Slager J, Aprianto R, Veening J-W. 2018. Deep genome annotation of the opportunistic human pathogen Streptococcus pneumoniae D39. Nucleic Acids Res 46:9971-9989.

13. Parsons JB, Frank MW, Eleveld MJ, Schalkwijk J, Broussard TC, Jonge MI de, Rock CO. 2015. A Thioesterase Bypasses the Requirement for Exogenous Fatty Acids in the plsX Deletion of Streptococcus pneumoniae. Mol Microbiol 96:28-41. 14. Kadioglu A, Echenique J, Manco S, Trombe MC, Andrew PW. 2003. The MicAB 
Two-Component Signaling System Is Involved in Virulence of Streptococcus pneumoniae. Infect Immun 71:6676-6679.

15. Dubrac S, Bisicchia P, Devine KM, Msadek T. 2008. A matter of life and death: Cell wall homeostasis and the WalKR (YycGF) essential signal transduction pathway. Mol Microbiol 70:1307-1322.

16. Winkler ME, Hoch JA. 2008. Essentiality, bypass, and targeting of the YycFG (VicRK) two-component regulatory system in gram-positive bacteria. J Bacteriol 190:2645-2648.

17. Blanchette KA, Shenoy AT, Milner II J, Gilley RP, Mcclure E, Hinojosa CA, Kumar N, Daugherty SC, Tallon LJ, Ott S, King SJ, Ferreira DM, Gordon SB, Tettelin H, Orihuela CJ. 2016. Neuraminidase A-Exposed Galactose Promotes Streptococcus pneumoniae Biofilm Formation during Colonization. Infect Immun 84:2922-2932.

18. Comella N, Grossman AD. 2005. Conservation of genes and processes controlled by the quorum response in bacteria: Characterization of genes controlled by the quorum-sensing transcription factor ComA in Bacillus subtilis. Mol Microbiol 57:1159-1174.

19. Dunman PM, Murphy E, Haney S, Palacios D, Tucker-Kellogg F, Wu S, Brown EL, Zagursky RJ, Shlaes D, Projan SJ. 2001. Transcription Profiling-Based Identification of Staphylococcus aureus Genes Regulated by the agr and/or sarA Loci. J Bacteriol 183:7341-7353.

20. Schuster M, Lostroh CP, Ogi T, Greenberg EP. 2003. Identification, Timing, and Signal Specificity of Pseudomonas aeruginosa Quorum-Controlled Genes: a Transcriptome Analysis. J Bacteriol 185:2066-2079.

21. Wagner VE, Bushnell D, Passador L, Brooks Al, Iglewski BH. 2003. Microarray Analysis of Pseudomonas aeruginosa Quorum-Sensing Regulons : Effects of Growth Phase and Environment. J Bacteriol 185:2080-2095.

22. Heydorn A, Nielsen AT, Hentzer M, Sternberg C, Givskov M, Ersbøll BK, Molin S. 2000. Quantification of biofilm structures by the novel computer program COMSTAT. Microbiology 146:2395-2407.

23. Miller JH. 1972. Assay of b-galactosidase, p. 352-355. In Miller, JH (ed.), Experiments in Molecular Genetics. Laboratory Press, Cold Spring Harbor, New York.

24. Bligh EG, Dyer WJ. 1959. A Rapid Method of Total Lipid Extraction and Purification. Can J Biochem Physiol 37:911-917. 
(A)

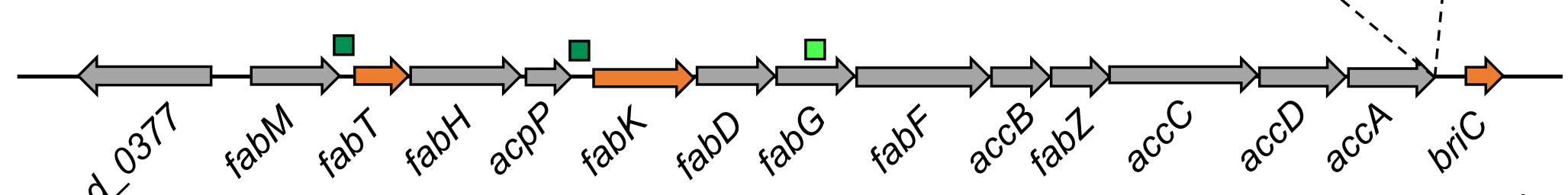
spl-

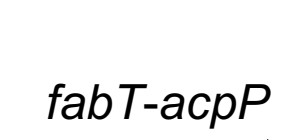

fabK-accA
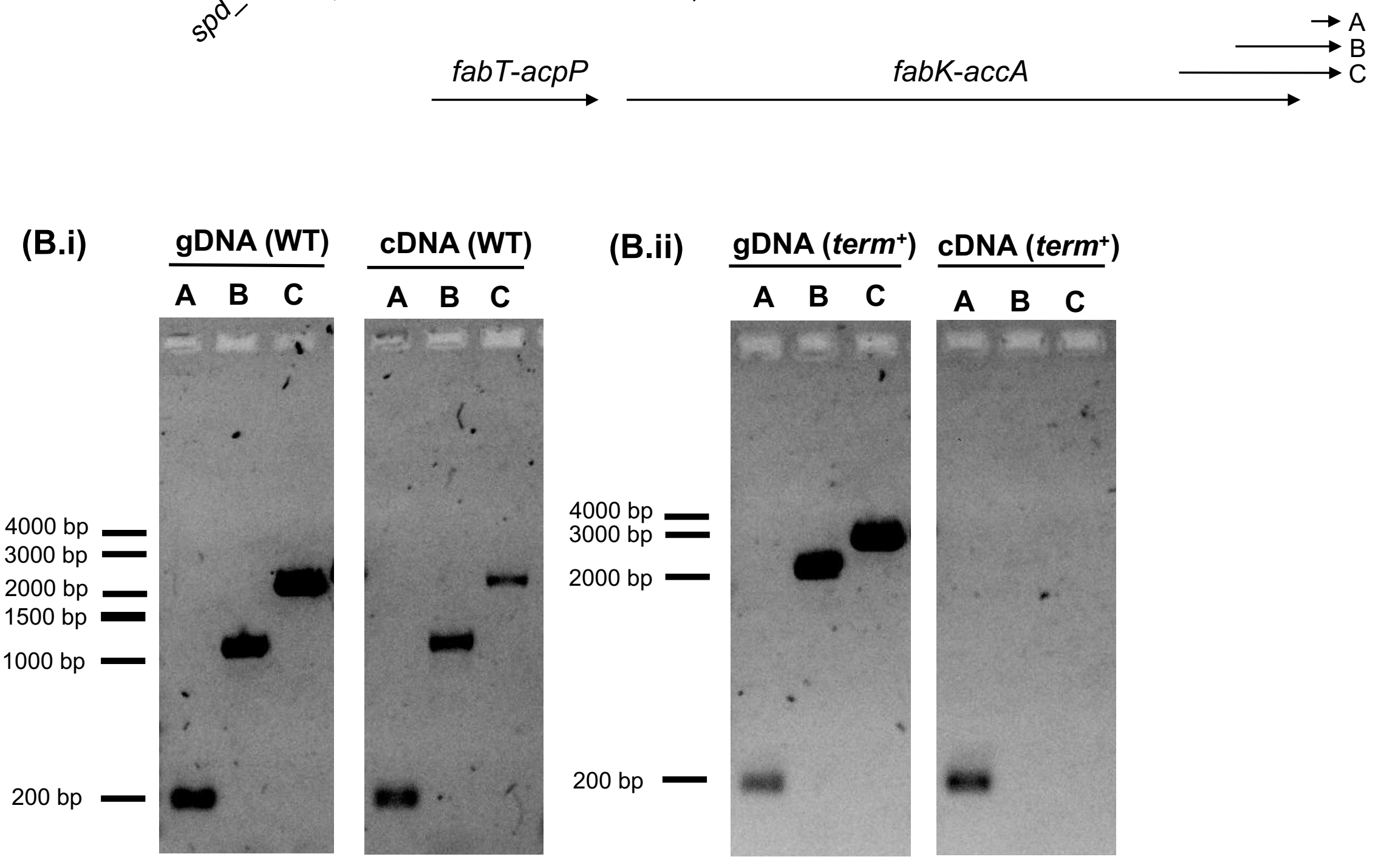
Figure 2

(A)
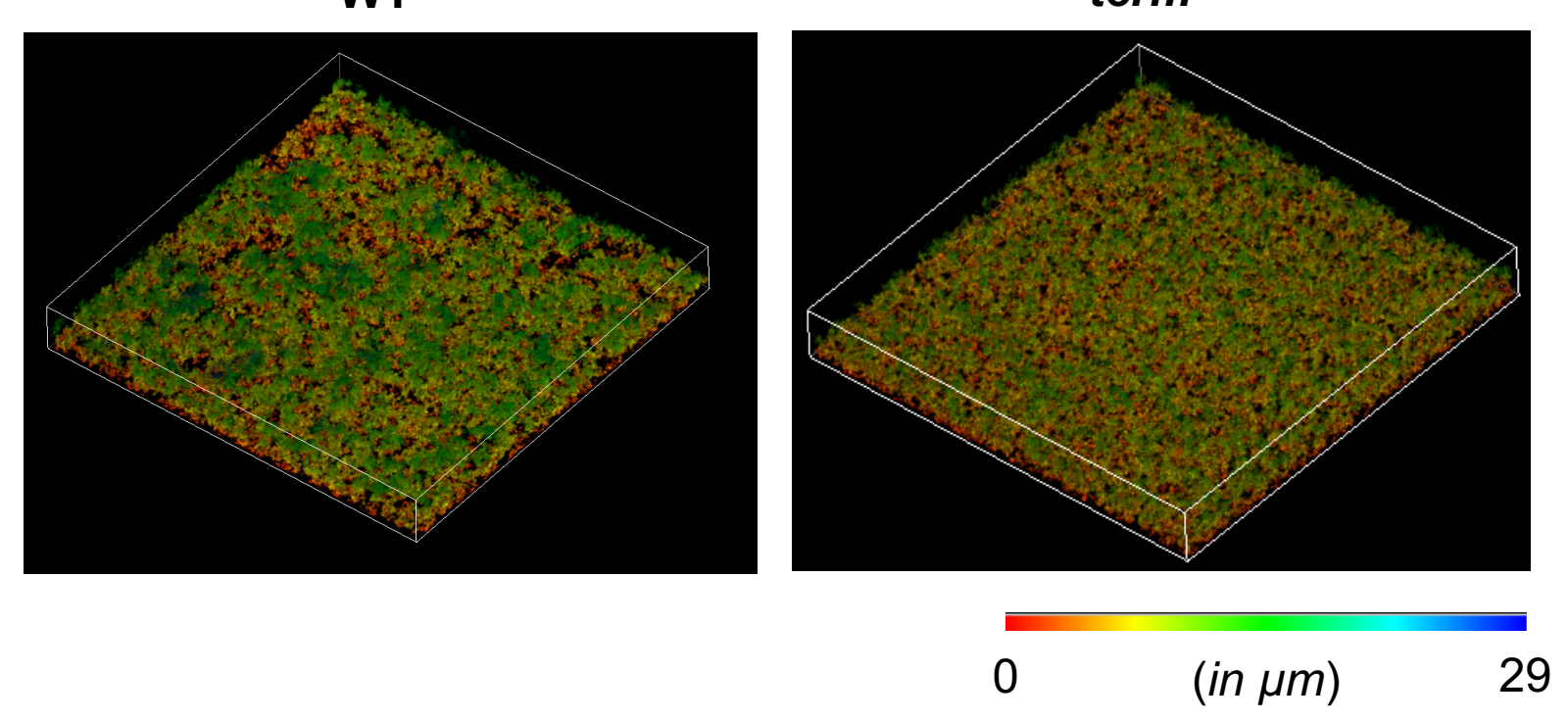

(B)
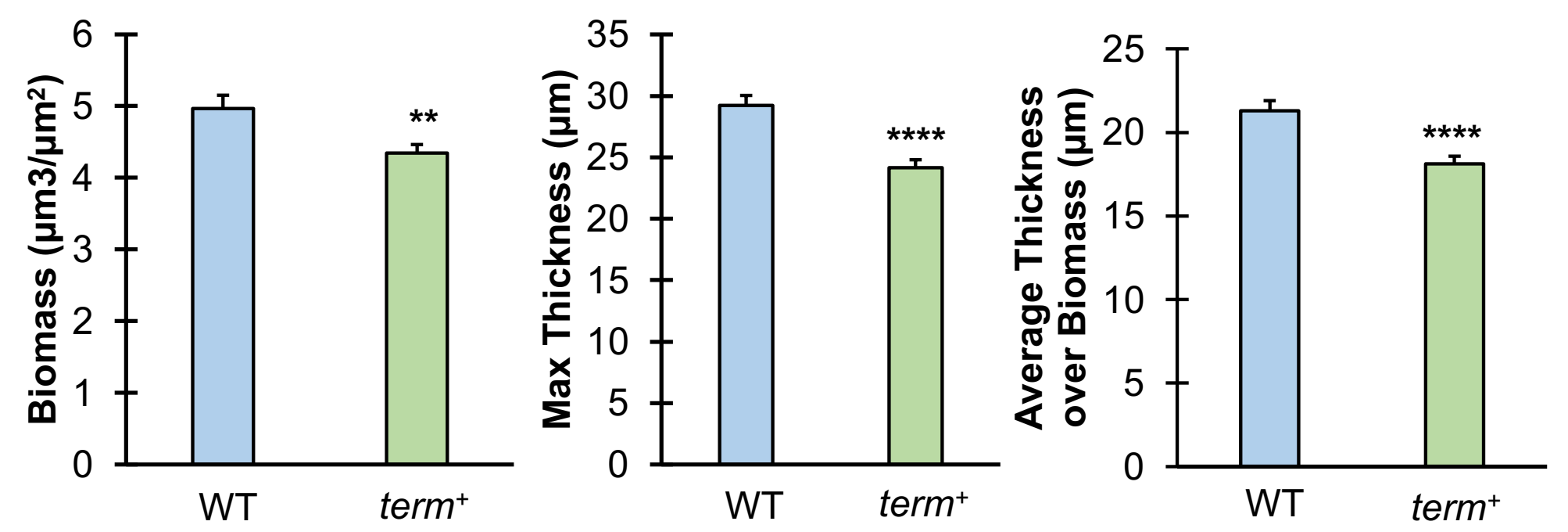
(C)

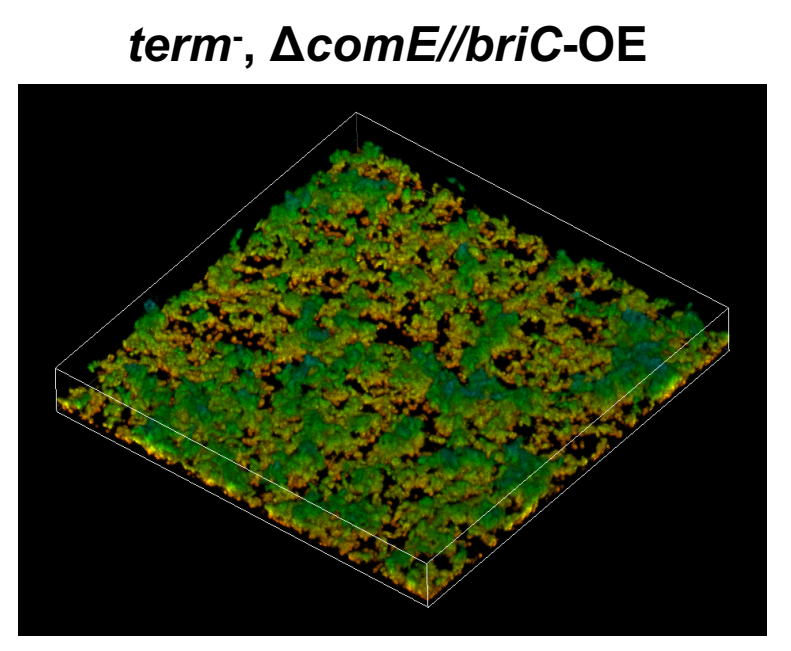

(D) term $^{+}, \Delta$ comE//bric-OE

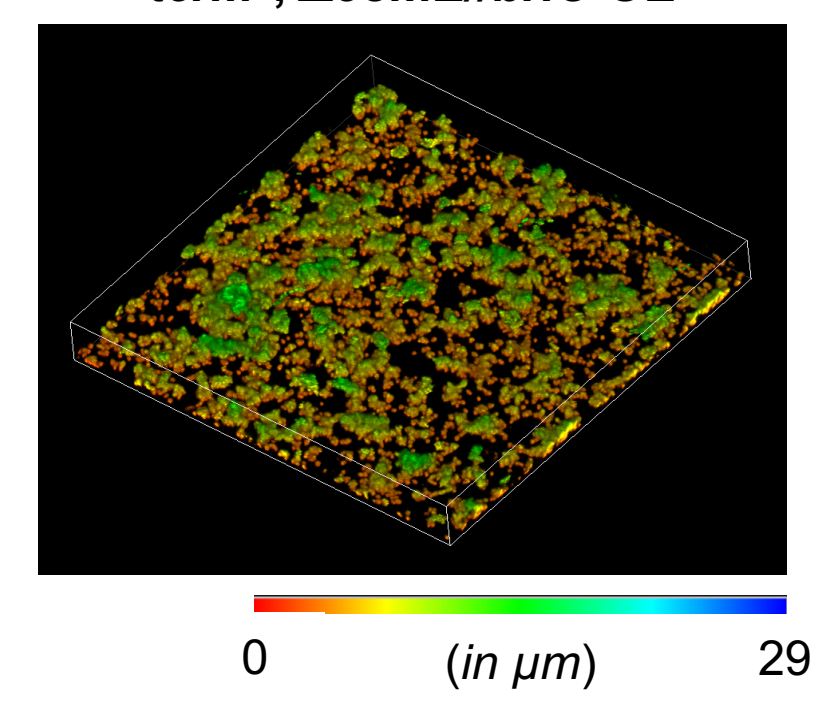

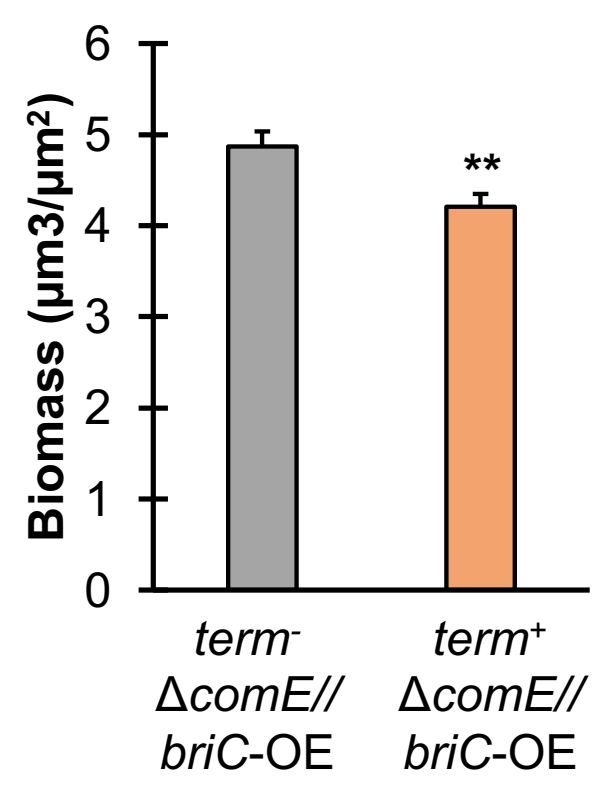

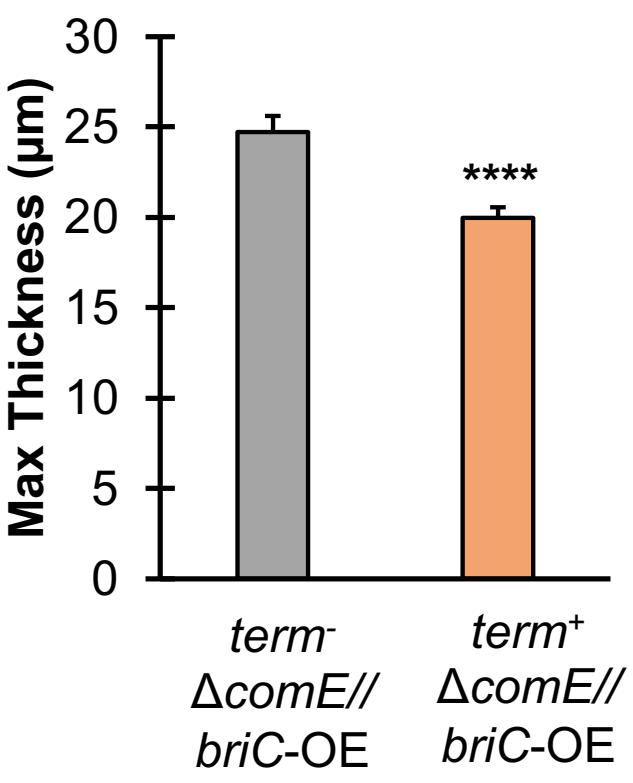

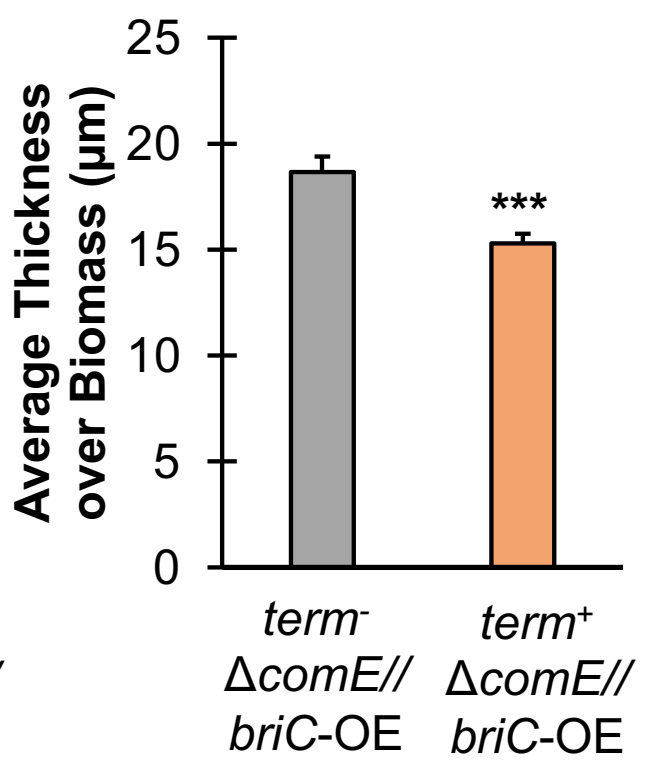


Figure 3

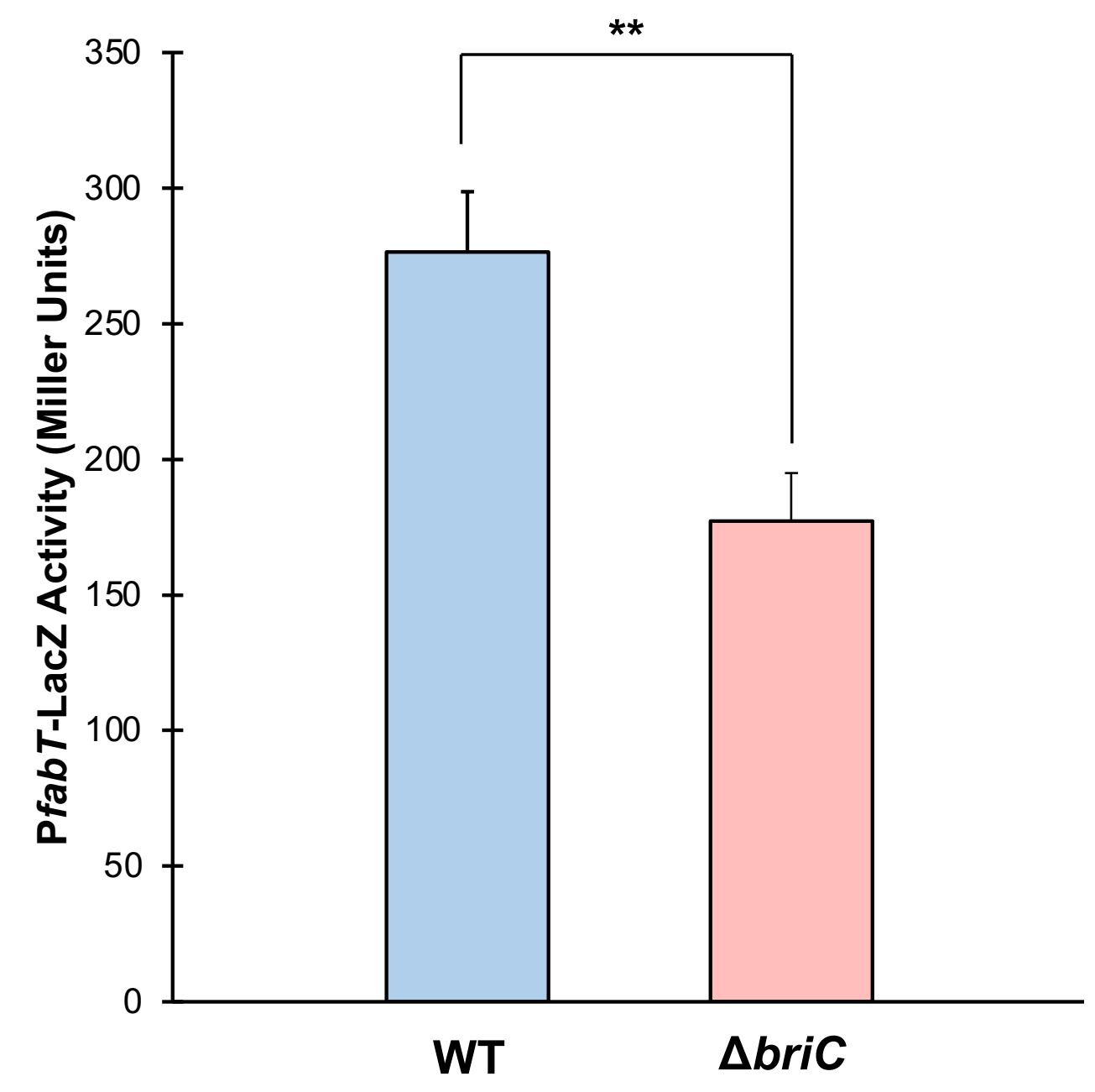




\section{Figure 4}
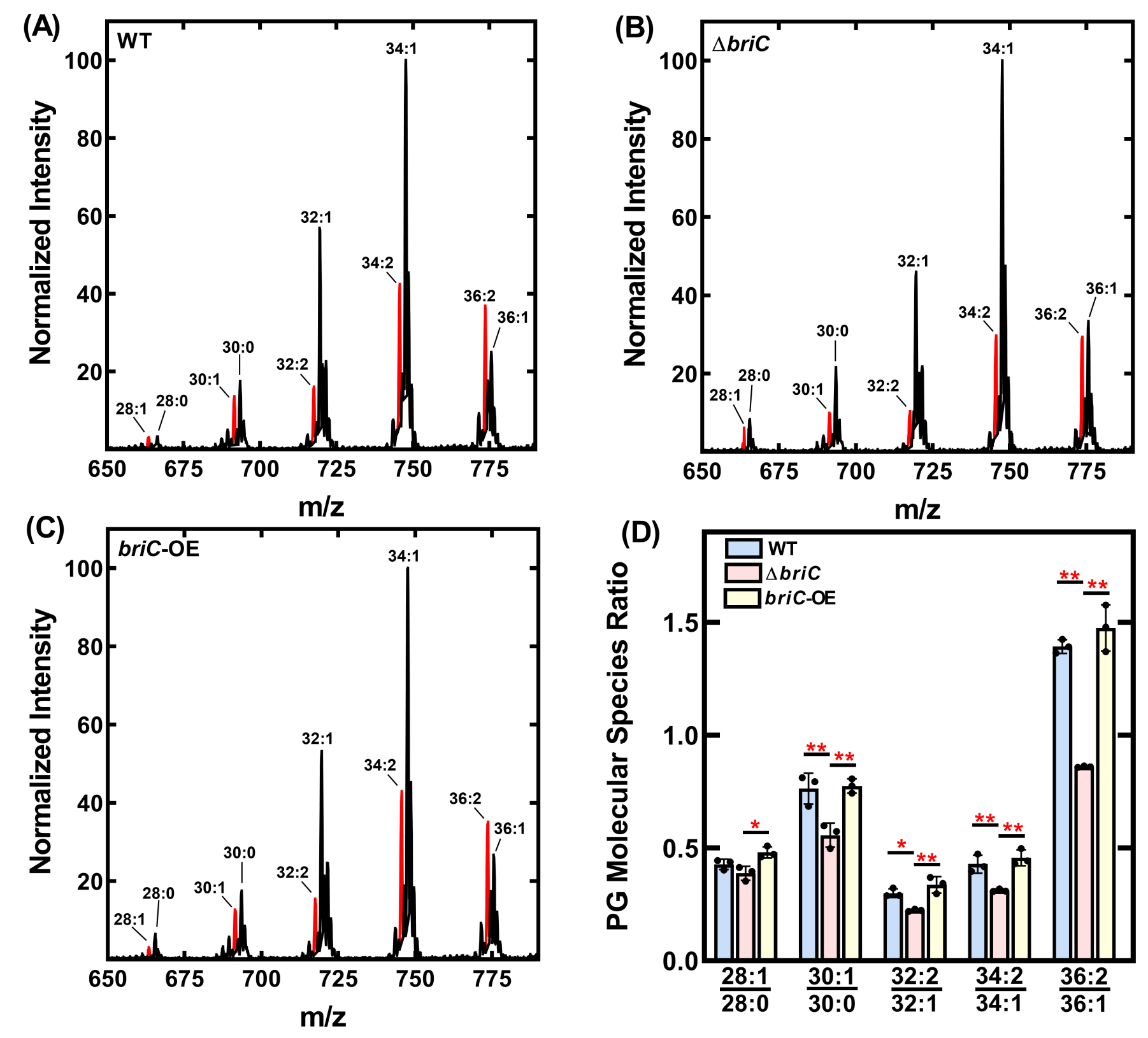
Table S1: Strains used in this experimental work

\begin{tabular}{|c|c|c|c|}
\hline Strain ID & Strain Name & \begin{tabular}{|l} 
Description \\
\end{tabular} & Source \\
\hline LH339 & R6D & $\begin{array}{l}\text { Penicillin-resistant R6- } \\
\text { derivative, Hun663.tr4 }\end{array}$ & $\begin{array}{l}\text { Severin et al. } \\
1996\end{array}$ \\
\hline LH65 & R6D $\Delta b r i C$ & $\begin{array}{l}\text { briC (spr_0388) replaced } \\
\text { with ermB in R6D; Ery }{ }^{R}\end{array}$ & $\begin{array}{l}\text { Aggarwal et al. } \\
2018\end{array}$ \\
\hline LH825 & term $^{+}$ & $\begin{array}{l}\text { ermB ligated with terminator } \\
\text { inserted downstream of accA } \\
\text { in R6D }\end{array}$ & This study \\
\hline LH366 & $\Delta \mathrm{comE} / / \mathrm{briC}-\mathrm{OE}$ & $\begin{array}{l}\text { comE }(\mathrm{spr} \text { 2041) replaced } \\
\text { with aad9 in R6D PbriC } \text { long- }^{-} \\
\text {briC; } \mathrm{Spec}^{\mathrm{R}}, \mathrm{Kan}^{\mathrm{R}}\end{array}$ & $\begin{array}{l}\text { Aggarwal et al. } \\
2018\end{array}$ \\
\hline LH845 & term $^{+}, \Delta$ comE//briC -OE & $\begin{array}{l}\text { ermB ligated with terminator } \\
\text { inserted downstream of accA } \\
\text { in } \Delta \text { comE }:: P b r i C_{\text {long-briC; }} \\
\text { Spec }^{\mathrm{R}}, \mathrm{Kan}^{\mathrm{R}}{ }^{\text {, Ery }}{ }^{\mathrm{R}}\end{array}$ & This study \\
\hline LH920 & $\begin{array}{l}\text { E. coli TOP10 (PfabK- } \\
\text { lacZ) }\end{array}$ & $\begin{array}{l}\text { E. coli strain transformed with } \\
\text { modified pPP2 containing } \\
\text { R6D fabK promoter fused } \\
\text { with lacZ; Kan }{ }^{\mathrm{R}}, \mathrm{Amp}^{\mathrm{R}}\end{array}$ & This Study \\
\hline LH921 & $\begin{array}{l}\text { E. coli TOP10 (PfabT- } \\
\text { lacZ) }\end{array}$ & $\begin{array}{l}\text { E. coli strain transformed with } \\
\text { modified pPP2 containing } \\
\text { R6D fabT promoter fused with } \\
\text { lacZ; } \mathrm{Kan}^{\mathrm{R}}, \mathrm{Amp}^{\mathrm{R}}\end{array}$ & This Study \\
\hline LH922 & R6D (PfabK-lacZ) & $\begin{array}{l}\text { R6D fabK promoter fused } \\
\text { with lacZ in R6D; Kan }{ }^{R}\end{array}$ & This Study \\
\hline LH925 & R6D (PfabT-lacZ) & $\begin{array}{l}\text { R6D fabT promoter fused with } \\
\text { lacZ in R6D; } \operatorname{Kan}^{\mathrm{R}}\end{array}$ & This Study \\
\hline LH928 & $\Delta b r i C($ PfabK-lacZ) & $\begin{array}{l}\text { R6D fabK promoter fused } \\
\text { with lacZ in R6D } \Delta b r i C \text {; Ery }{ }^{R} \text {, } \\
\text { Kan }^{R}\end{array}$ & This Study \\
\hline LH931 & $\Delta b r i C$ (PfabT-lacZ) & $\begin{array}{l}\text { R6D fabT promoter fused with } \\
\text { lacZ in R6D } \Delta b r i C ; \text { Ery }^{\mathrm{R}} \text {, } \\
\mathrm{Kan}^{\mathrm{R}}\end{array}$ & This Study \\
\hline LH360 & R6D::PbriC long $-b r i C$ & $\begin{array}{l}\text { briC, along with PN4595-T23 } \\
\text { briC promoter inserted } \\
\text { downstream of bga in R6D; } \\
\text { Kan }^{R}\end{array}$ & $\begin{array}{l}\text { Aggarwal et al. } \\
2018\end{array}$ \\
\hline
\end{tabular}


Table S2: Primers used in this study

\begin{tabular}{|c|c|c|c|c|}
\hline $\begin{array}{l}\text { Primer } \\
\text { No. }\end{array}$ & Primer & Sequence & $\begin{array}{l}\text { Strain } \\
\text { Constructed }\end{array}$ & $\begin{array}{l}\text { Restriction } \\
\text { Site (if } \\
\text { present) }\end{array}$ \\
\hline SDA210 & $\begin{array}{l}\text { term }^{+} \text {Flank } \\
1 \mathrm{~F}\end{array}$ & $\begin{array}{l}\text { ATGGCTCTATTTAGTAAAAAAG } \\
\text { ATAAGTATATTCGAATC }\end{array}$ & $\begin{array}{l}\text { term }^{+} \& \text { term }^{+} \\
\Delta \text { comE ::PbriC } \text { long }^{-} \\
\text {briC }\end{array}$ & \\
\hline SDA224 & $\begin{array}{l}\text { term } \\
1 \mathrm{R}\end{array}$ & $\begin{array}{l}\text { AGGAATTAATCTAACTTAGTAT } \\
\text { TTTCTAAATCGTTGATAGCGTT } \\
\text { CTTC }\end{array}$ & $\begin{array}{l}\text { term }^{+} \& \text { term }^{+} \\
\Delta{\text { comE }:: \text { PbriC }_{\text {long }}^{-}} \\
\text {briC }\end{array}$ & \\
\hline SDA225 & $\mid \begin{array}{l}\text { term } \\
\text { F ermB }\end{array}$ & $\begin{array}{l}\text { TTTAGAAAATACTAAGTTAGAT } \\
\text { TAATTCCTACCAGTGACTAAT } \\
\text { CTTATG }\end{array}$ & $\begin{array}{l}\text { term }^{+} \& \text { term }^{+} \\
\text {}{\text { comE }:: \text { PbriC }_{\text {long }}^{-}}_{\text {briC }}\end{array}$ & \\
\hline SDA226 & $\begin{array}{l}\text { term } \\
\mathrm{R}\end{array}$ & $\begin{array}{l}\text { GCGGGGTTTTTTCGCTACCCC } \\
\text { TTATCGATACAAATTCCC }\end{array}$ & $\begin{array}{l}\text { term }^{+} \& \text { term }^{+} \\
\Delta \text { comE ::PbriC } \text { long }^{-} \\
\text {briC }\end{array}$ & \\
\hline SDA227 & $\begin{array}{l}\text { term }^{+} \text {Flank } \\
2 \mathrm{~F}\end{array}$ & $\begin{array}{l}\text { TATCGATAAGGGGTAGCGAAA } \\
\text { AAACCCCGCCGAAG }\end{array}$ & $\begin{array}{l}\text { term }^{+} \& \text { term }^{+} \\
\Delta{\text { comE }:: \text { PbriC }_{\text {long }}^{-}}_{\text {briC }}\end{array}$ & \\
\hline SDA228 & $\begin{array}{l}\text { term }^{+} \text {Flank } \\
2 \mathrm{R}\end{array}$ & $\begin{array}{l}\text { ATGCGCTTTTCAAGCTCTCAT } \\
\text { G }\end{array}$ & $\begin{array}{l}\text { term }^{+} \text {\& } \text { term }^{+} \\
\Delta \text { comE ::PbriC } \text { long }^{-} \\
\text {briC }\end{array}$ & \\
\hline SDA245 & PfabK F & $\begin{array}{l}\text { ATATATGGTACCGCAGAATAT } \\
\text { TAGTAGAAGGAGTAGG }\end{array}$ & \begin{tabular}{|l} 
E. coli TOP10 \\
(PfabK-lacZ)
\end{tabular} & Kpnl \\
\hline SDA246 & PfabK R & $\begin{array}{l}\text { ATATATTCTAGAAGTGCCTCC } \\
\text { AACCTTCC }\end{array}$ & \begin{tabular}{|l|} 
E. coli TOP10 \\
(PfabK-lacZ) \\
\end{tabular} & Xbal \\
\hline SDA247 & PfabT F & $\begin{array}{l}\text { ATATATGGTACCAAAATCCTT } \\
\text { GCATCATTCTTTG }\end{array}$ & \begin{tabular}{|l|} 
E. coli TOP10 \\
(PfabT-lacZ) \\
\end{tabular} & Kpnl \\
\hline SDA248 & Pfabt R & $\begin{array}{l}\text { ATATATTCTAGATTTTCATATC } \\
\text { ССTCСTTCTTCA }\end{array}$ & \begin{tabular}{|l|} 
E. coli TOP10 \\
(PfabT-lacZ) \\
\end{tabular} & Xbal \\
\hline SDA47 & fabZ-bric F & $\begin{array}{l}\text { AGATTGAAGGAGTGCAGAC } \\
\text { CAATG }\end{array}$ & $\begin{array}{l}\text { N/A (Transcript } \\
\text { Check) }\end{array}$ & \\
\hline SDA51 & accD-briC F & $\begin{array}{l}\text { AATCCCAATCGTTCGGTTA } \\
\text { GG }\end{array}$ & $\begin{array}{l}\text { N/A (Transcript } \\
\text { Check) }\end{array}$ & \\
\hline SDA178 & accA-briC F & $\begin{array}{l}\text { ATGAATATTGCAAAAATAG } \\
\text { TCAGAGAAG }\end{array}$ & $\begin{array}{l}\text { NA (Transcript } \\
\text { Check) }\end{array}$ & \\
\hline SDA195 & briC F & $\begin{array}{l}\text { AAGAAGGTACTTGCAATGA } \\
\text { CAGGTACAAATACATTTAC } \\
\text { AGTTCTTTC }\end{array}$ & $\begin{array}{l}\text { NA (Transcript } \\
\text { Check) }\end{array}$ & \\
\hline SDA111 & bric R & TGTTCGGAAGCCGTACTT & $\begin{array}{l}\text { NA (Transcript } \\
\text { Check) }\end{array}$ & \\
\hline
\end{tabular}

